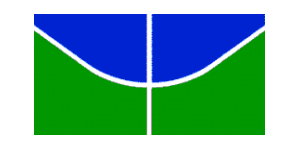

Universidade de Brasília

Faculdade de Economia, Administração, Contabilidade e Gestão de Políticas Públicas (FACE)

Departamento de Ciências Contábeis e Atuariais

Ciências Contábeis

PEDRO HENRIQUE SILVA MARIZ

Exame de Suficiência Contábil x ENADE: Uma análise de correspondência dos resultados dos alunos de Ciências Contábeis das instituições públicas e privadas do Brasil

Brasília - DF 
Professora Doutora Márcia Abrahão Moura

Reitora da Universidade de Brasília

Professor Doutor Enrique Huelva Unternbäumen

Vice-Reitor da Universidade de Brasília

Professor Doutor Sérgio Antônio Andrade de Freitas

Decano de Ensino de Graduação

Professor Doutor Eduardo Tadeu Vieira

Diretor da Faculdade de Economia, Administração, Contabilidade e Gestão de Políticas Públicas

Professor Doutor Paulo César de Melo Mendes

Chefe do Departamento de Ciências Contábeis e Atuariais

Professora Doutora Danielle Montenegro Salamone Nunes

Coordenadora de Graduação do curso de Ciências Contábeis - Diurno

Professor Mestre Elivânio Geraldo de Andrade

Coordenador de Graduação do curso de Ciências Contábeis - Noturno 


\section{Exame de Suficiência Contábil x ENADE: Uma análise de correspondência dos resultados dos alunos de Ciências Contábeis das instituições públicas e privadas do Brasil}

Trabalho de conclusão de curso apresentado à Faculdade de Economia, Administração, Contabilidade e Gestão de Políticas Públicas (FACE) da Universidade de Brasília como requisito parcial à obtenção do título de Bacharel em Ciências Contábeis.

Orientadora: Prof. Dr. Beatriz Fátima Morgan.

Brasília - DF 
Mariz, Pedro Henrique Silva

Exame de Suficiência Contábil x ENADE: Uma análise de correspondência dos resultados dos alunos de Ciências Contábeis das instituições públicas e privadas do Brasil / Pedro Henrique Silva Mariz, 2019, 40p.

Orientadora: Prof. Dr. Beatriz Fátima Morgan

Trabalho de Conclusão de Curso (Graduação em Ciências Contábeis) - Universidade de Brasília, Faculdade de Economia, Administração, Contabilidade e Gestão de Políticas Públicas, Departamento de Ciências Contábeis e Atuariais - Brasília, 2019.

1. ENADE 2. Exame de Suficiência 3. Faculdades públicas e privadas 


\title{
Exame de Suficiência Contábil x ENADE: Uma análise de correspondência dos resultados dos alunos de Ciências Contábeis das instituições públicas e privadas do Brasil
}

\begin{abstract}
Trabalho de conclusão de curso apresentado à Faculdade de Economia, Administração, Contabilidade e Gestão de Políticas Públicas (FACE) da Universidade de Brasília como requisito parcial à obtenção do título de Bacharel em Ciências Contábeis.
\end{abstract}

Orientadora: Prof. Dr. Beatriz Fátima Morgan.

Aprovado em__de___ de 2019.

Banca examinadora

Professora Doutora Beatriz Fátima Morgan

Professora-Orientadora

Professor Doutor José Lúcio Tozetti Fernandes

Professor-Avaliador

Brasília - DF 


\section{RESUMO}

O estudo objetivou verificar se existe relação entre os desempenhos obtidos no Exame de Suficiência Contábil e no Exame Nacional de Desempenho dos Estudantes (ENADE) e identificar possíveis disparidades entre as instituições de ensino público e privado. Foram coletados dados do INEP referentes à qualificação das faculdades de acordo com seu conceito ENADE do ano de 2015 e dados do CFC referentes aos aprovados no Exame de Suficiência na primeira edição de 2017. Inicialmente foram realizadas análises descritivas acerca do tema e, posteriormente, optou-se pela análise de correspondência. A amostra foi de 891 organizações que ofertam o curso de ciências contábeis no Brasil, sendo elas divididas em 112 públicas e 779 privadas. Após realizada a análise de correspondência, constatou-se que as instituições de ensino privadas têm associações mais fortes com o conceito ENADE 3 e, de 20 a $29 \%$ de aprovação no Exame de suficiência contábil, enquanto as instituições públicas são mais associadas ao conceito ENADE 5 e possuem de 90 a $100 \%$ de aprovação no exame. Este estudo contribui para a área de educação em contabilidade, pois a partir de seus métodos quantitativos e ampla base de dados, compara dois objetos de avaliação aos quais as IES são submetidas e identifica diferenças entre as organizações públicas e privadas a fim de melhorar a qualidade de ensino no país.

Palavras-chave: ENADE. Exame de Suficiência Contábil. Instituições públicas e privadas. 


\begin{abstract}
The study aimed to verify the existence of an association between the performances obtained in the Examination of Accounting Sufficiency and the National Examination of Student Performance (ENADE) and to identify possible disparities between public and private education institutions. Data were collected from INEP, refering to the qualification of the faculties according to their ENADE concept of the year 2015 and data of the CFC, refering to those approved in the Examination of Sufficiency in the first edition of 2017. Descriptive analyzes were performed with the collected data and, later, statistical correspondence analysis. The sample was of 891 organizations that offer the course of accounting sciences in Brazil, being divided in 112 public and 779 private. After the analysis of correspondence, it was found that private educational institutions have stronger associations with the ENADE 3 concept, and from 20 to $29 \%$ of passing the Accounting sufficiency exam, while public institutions are more associated with the ENADE concept 5 and have 90 to $100 \%$ passing the exam. This study contributes to the area of accounting education because, based on its quantitative methods and a large database, it compares two evaluation objects to which High Educations Institutions are submitted and identifies differences between public and private organizations in order to improve quality in the country.
\end{abstract}

Keywords: ENADE. Examination of Accounting Sufficiency. Public and private institutions. 


\section{SUMÁRIO}

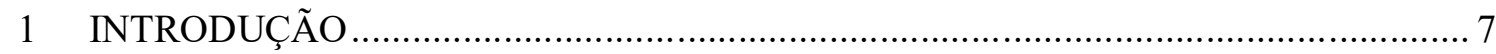

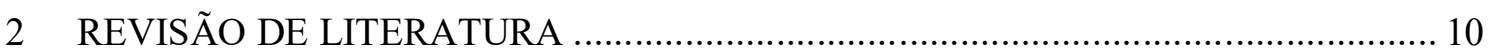

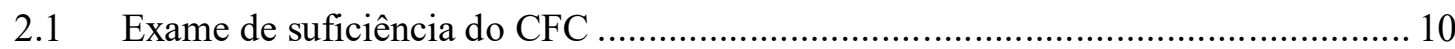

2.2 Exame Nacional de Desempenho dos Estudantes (ENADE) …………………….... 12

2.3 Avaliação ENADE x Avaliação do Conselho Federal de Contabilidade ................... 13

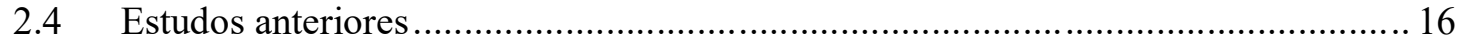

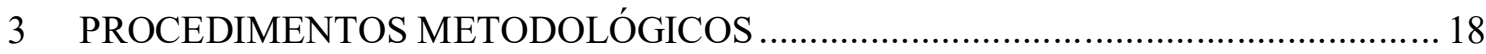

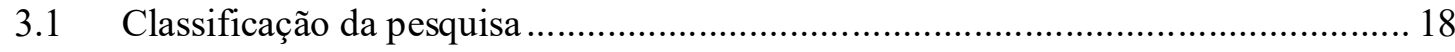

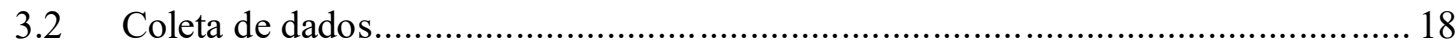

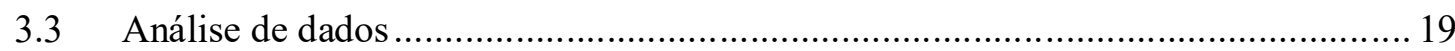

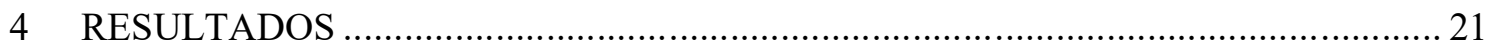

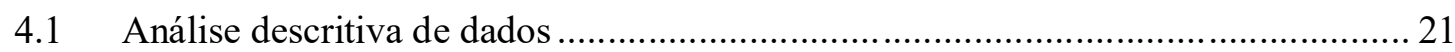

4.2 Análise de correspondência dos dados .................................................................. 25

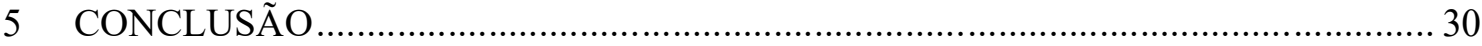

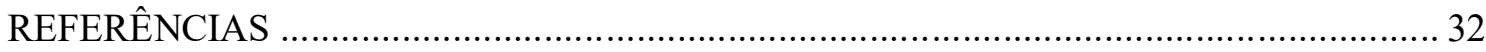

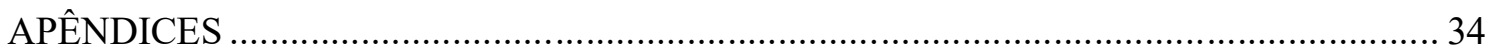




\section{INTRODUÇÃO}

A crescente competitividade do mercado exige do profissional de qualquer área do conhecimento um alto nível de capacitação, de forma que profisssionais que não acompanham essa evolução tendem perder seu espaço para atuação (SOUZA, 2017). O mercado exige que o profissional contábil seja dinâmico e possua uma formação abrangente, passando de executor a gestor da informação contábil e, assim, auxiliando verdadeiramente no crescimento das empresas (PAIVA; ROSA, 2016). Deste modo, infere-se que a escola contábil vem se modernizando e se adaptando às mudanças da economia globalizada, por meio de diversas alterações nas normas contábeis (SOUZA, 2017; BUGARIM et al., 2014).

As instituições de ensino superior devem viabilizar aos seus alunos o desenvolvimento das competências necessárias à atuação profissional (SILVA; MIRANDA; PEREIRA, 2017). Com o crescente aumento do nível de capacitação exigido pelo mercado e, consequentemente, da procura por uma formação acadêmica, multiplicaram-se as ofertas de cursos superiores no Brasil, tanto de instituições públicas quanto privadas (BLUM et al., 2018). Esse crescimento, no entanto, se deu de forma mais quantitativa que qualitativa, dando origem à necessidade de se avaliar a qualidade do ensino fornecido por essas organizações (PAIVA; ROSA, 2016).

A avaliação do ensino decorre de duas concepções essencialmente contraditórias: a técnica e a política. A primeira, fomentada por esferas do âmbito acadêmico, preocupa-se com a construção e a consolidação de uma universidade socialmente relevante; a segunda, estimulada por agentes financeiros internacionais e políticas governamentais, busca medir produtividade e eficiência (PINHEIRO et al., 2013). No Brasil, a quantidade de ingressantes nos cursos superiores tem crescido significativamente, demandando uma maior responsabilidade do Estado para executar essa avaliação (SILVA et al., 2017).

Assim, em meados da década de 90, o governo brasileiro deu início à gradual implantação de um sistema de avaliação conhecido como "provão", amplamente criticado à época. Na década seguinte, formou-se a Comissão Especial de Avaliação da Educação (CEA), que em agosto de 2003 propôs um novo mecanismo denominado Sistema Nacional de Avaliação da Educação Superior (SINAES) - formalmente instituído por lei federal em abril de 2004 (SILVA, 2015). 
O novo sistema incluía uma diferente abordagem para a avaliação de cursos superiores, o atualmente adotado Exame Nacional de Desempenho dos Estudantes (ENADE), cujo responsável pela aplicação é o Instituto Nacional de Estudos e Pesquisas Educacionais Anísio Teixeira/Ministério da Educação e Cultura (Inep/MEC). O ENADE avalia diversos cursos e busca classificá-los de acordo com o conhecimento demonstrado por seus alunos. $\mathrm{O}$ exame ocorre todo ano alternando os cursos avaliados de forma que sua reavaliação ocorre a cada três anos.

No Brasil, o ensino da contabilidade passou por uma evolução sem precedentes, desafiando as instituições que disponibilizam o curso a fornecer aos seus alunos uma educação de qualidade que acompanhe a realidade mundial (BUGARIM et al., 2014). Diante desse cenário, o Conselho Federal de Contabilidade (CFC), que é a associação da classe contábil brasileira, desenvolveu o Exame de Suficiência Contábil, aplicado pelo Conselho Federal de Contabilidade (CFC) aos graduados em Ciências Contábeis como requisito à obtenção do registro para o exercício da profissão, instituído pelo art. 12 do Decreto-Lei no 9.295/46, com redação dada pela Lei no 12.249/2010.

A obrigatoriedade do exame de suficiência contábil corrobora com o entendimento de que há conhecimentos mínimos necessários para o exercício da profissão de contador, o que contribui intimamente para o desenvolvimento e qualificação dos cursos de bacharelado em ciências contábeis no Brasil (SOUZA, 2017). Vale ressaltar que para a aprovação no Exame o participante precisa acertar pelo menos 50\% das questões (CFC, 2017), fator que pode influenciar na melhoria do desempenho dos alunos tanto neste exame como no supracitado ENADE (SOUZA, 2017).

Nesse contexto, observa-se a importância de suscitar a reflexão acerca dos atuais mecanismos de avaliação da educação superior brasileira, uma vez que a eficácia desses métodos se refletirá no progresso da qualidade desse setor de ensino. Portanto, esse estudo objetiva verificar se há relação entre os desempenhos obtidos no ENADE e no exame de suficiência contábil e identificar possíveis disparidades entre instituições de ensino públicas e privadas, a fim de possibilitar o aperfeiçoamento tanto dos métodos de ensino das instituições de ensino superior quanto dos de avaliação adotados pelo Estado.

O presente estudo se divide em cinco seções. São elas: introdução, que inclui o objetivo, justificativa e a relevância do estudo; revisão da literatura, que explora a atual 
conjuntura do ENADE e do exame de suficiência contábil; aspectos metodológicos; resultados e análise dos dados; e, por fim, as conclusões acerca do estudo. 


\section{REVISÃO DE LITERATURA}

A presente revisão de literatura aborda o exame de suficiência do $\mathrm{CFC}$, atualmente exigido para o exercício da profissão contábil, o Exame Nacional de Desempenho dos Estudantes (ENADE), bem como a legislação sob a qual se fundamentam ambos os mecanismos e os estudos anteriores realizados. Pretende-se, assim, promover a melhor compreensão acerca dos principais métodos de avaliação do ensino da contabilidade atualmente aplicados no país e sua importância para a educação superior.

\subsection{Exame de suficiência do CFC}

Criado em 1999, o Exame de Suficiência Contábil é uma prova cujo objetivo é atestar o ganho de conhecimentos médios do graduado em ciências contábeis, isto é, o mínimo necessário ao desempenho das atividades de contador. De acordo com a Resolução no 853/99 do $\mathrm{CFC}$, é requisito obrigatório para a obtenção do registro profissional de contabilidade para bacharéis e técnicos em contabilidade e, para que ocorra a aprovação, o participante deve acertar ao menos $50 \%$ do conteúdo da prova.

No que se refere ao seu conteúdo programático, a Resolução n ${ }^{\circ}$ 1373/2011 do CFC estabelece que as provas para os bacharéis em Ciências Contábeis abrangem as seguintes áreas de conhecimento:

(i) Contabilidade Geral;

(ii) Contabilidade de Custos;

(iii) Contabilidade Aplicada ao Setor Público;

(iv) Contabilidade Gerencial;

(v) Controladoria;

(vi) Teoria da Contabilidade; 
(vii) Legislação e Ética profissional;

(viii) Princípios de Contabilidade e Normas Brasileiras de Contabilidade;

(ix) Auditoria Contábil;

(x) Perícia Contábil;

(xi) Noções de Direito;

(xii) Matemática Financeira e Estatística;

(xiii) e, Língua Portuguesa.

Uma das principais motivações para a criação do teste foi a preocupação com a qualidade do serviço contábil brasileiro (BROIETTI, 2014). O exame, no entanto, provocou diversos debates por não possuir status de lei, mas de resolução do CFC. A obrigatoriedade do exame também gerou discussão, uma vez que alguns a consideravam inconstitucional, sob o argumento de que feria o princípio constitucional do livre exercício profissional. Sem lei que normatizasse o Exame de Suficiência, em 2005 o exame deixou de ser obrigatório (PINHEIRO; BONFIM; PORTUGAL, 2013; OLIVEIRA NETO; KUROTORI, 2009).

Em 2010, a partir da publicação da Resolução $\mathrm{n}^{\circ} 1301$ do CFC e da promulgação da lei 12.249/10, o Exame de Suficiência Contábil retomou sua obrigatoriedade (PINHEIRO; BONFIM; PORTUGAL, 2013). Observa-se, desde então, que a existência de uma nota mínima para aprovação no exame contribui para o desenvolvimento e qualificação do curso de bacharel em ciências contábeis, tendo em vista que demanda do aluno maior disposição durante as aulas, levando à melhor assimilação o conteúdo ministrado (MARTINS, et al., 2003), além de aumentar a atenção das universidades para o programa de graduação (BROIETTI, 2014). 


\subsection{Exame Nacional de Desempenho dos Estudantes (ENADE)}

O Exame Nacional de Desempenho dos Estudantes (ENADE) é um dos pilares do Sistema Nacional de Avaliação da Educação Superior (SINAES), criado pela Lei $\mathrm{n}^{\circ} 10.861$, de 14 de abril de 2004, visando mensurar as competências e habilidades acadêmicas necessárias à formação geral e profissional dos estudantes adquiridas no decorrer de seus respectivos cursos de ensino superior (INEP, 2015).

O exame se divide em itens de formação geral (FG) e componente específico (CE). Os itens do tipo FG são comuns a todas as áreas de formação e buscam avaliar "a formação de um profissional ético, competente e comprometido com a sociedade em que vive" (INEP, 2015), enquanto as do tipo CE objetivam analisar a qualidade do processo de formação do aluno a partir da observância das competências predefinidas pelas comissões de especialistas da área de cada curso avaliado, fundamentadas em suas respectivas diretrizes curriculares (SANTOS; AFONSO, 2016).

Para tanto, dois grupos de estudantes em momentos distintos de sua graduação são designados para o exame - os ingressantes, que devem ter cursado até o fim do primeiro ano; e os concluintes, que se situam até o final do último ano do curso. Ambos os grupos se deparam com as mesmas questões ao realizar a prova, com o objetivo de avaliar a evolução acadêmica dos discentes ao longo da graduação (SANTOS; AFONSO, 2016). A prova é obrigatória para os alunos selecionados e pré-requisito para a emissão do histórico escolar desses, devendo ser aplicada com intervalo máximo de três anos, em conformidade com a legislação supracitada (JESUS, 2017).

Ainda que seja um mecanismo de avaliação oficial do Ministério da Educação, a eficácia do ENADE é frequentemente discutida no meio acadêmico, onde divide opiniões. Os principais debates acerca do método referem-se aos reiterados boicotes promovidos pelos estudantes, que somente comparecem ao exame para obterem acesso ao diploma, deixando os gabaritos em branco; e à dificuldade de se avaliar com eficiência um curso extenso através de um único exame composto por 40 questões. Há, no entanto, um consenso sobre a importância da existência de um método de avaliação que conduza à melhora da qualidade do ensino superior do país (SANTOS et al., 2014). 


\subsection{Avaliação ENADE x Avaliação do Conselho Federal de Contabilidade}

De acordo com a nota técnica $n^{\circ} 2$ de 2017 do INEP, o conceito ENADE é um indicador de desempenho que avalia a qualidade do curso oferecido pelas instituições de ensino superior baseado nos resultados obtidos pelos estudantes na prova. Desde 2008, os cálculos para a classificação das IES consideram apenas os estudantes que compareceram ao exame.

Antes calculado para cada Unidade de Observação, constituída pelo conjunto de cursos que compõem uma área específica, o conceito ENADE, a partir de 2015, começa a ser calculado para cada curso separadamente. Para o cálculo, todas as medidas são padronizadas e reescalonadas para assumirem valores de 0 a 5 como variáveis contínuas. Esse processo passa por dois estágios, o cálculo do afastamento padronizado de cada curso de graduação e a transformação dos afastamentos em notas padronizadas (INEP, 2017).

A próxima etapa para o cálculo do conceito é a obtenção do desempenho médio dos concluintes na Formação Geral (FG) e Componente Específico (CE) do exame, seguida da obtenção da média nacional das áreas de avaliação em FG e CE. Posteriormente, é calculado o desvio padrão de cada área de avaliação e os afastamentos padronizados em FG e CE de cada curso de graduação, obtendo-se assim, uma nota padronizada para cada curso que variam entre 0 e 5 (INEP, 2017).

A nota do conceito ENADE é uma média ponderada das notas padronizadas do curso de graduação em Formação Geral e Componente Específico, sendo o peso dividido em 25\% e $75 \%$, respectivamente. Assim, para a classificação das IES, o conceito ENADE (faixa) assume valores de 1 a 5, como mostrado no quadro 1, decorrente da conversão da nota dos concluintes dos cursos de graduação (INEP, 2017). 
Quadro 1. Notas dos concluintes e suas respectivas faixas.

\begin{tabular}{|c|c|}
\hline $\begin{array}{c}\text { Conceito Enade } \\
\text { (Faixa) }\end{array}$ & $\begin{array}{c}\boldsymbol{N} \boldsymbol{C}_{\boldsymbol{c}} \\
\text { (Valor Contínuo) }\end{array}$ \\
\hline 1 & $0 \leq N C_{c}<0,945$ \\
\hline 2 & $0,945 \leq N C_{c}<1,945$ \\
\hline 3 & $1,945 \leq N C_{c}<2,945$ \\
\hline 4 & $2,945 \leq N C_{c}<3,945$ \\
\hline 5 & $3,945 \leq N C_{c} \leq 5$ \\
\hline
\end{tabular}

Fonte: INEP (2017).

Já o exame de suficiência contábil (ESC), de acordo com Schmitz (2008), avalia os alunos do curso de ciências contábeis e tem como principal objetivo verificar as habilidades, capacidades e aptidões desenvolvidas no curso realizado através de conteúdos programáticos. Ou seja, é um teste que busca comprovar que o estudante possui o conhecimento mínimo necessário para exercer a profissão.

A Fundação Brasileira de Contabilidade é a instituição responsável pela sua aplicação, que ocorre semestralmente. $\mathrm{O}$ teste consiste em 50 questões objetivas que abordam conteúdos de diferentes áreas do conhecimento em contabilidade com quatro opções de resposta cada. A aprovação dos concluintes requer o acerto de $50 \%$ ou mais da prova (CFC, 2017).

De acordo com Silva (2015), apesar de tratarem de assuntos que variam constantemente, as avaliações se mostram significativamente semelhantes, o que pode ser melhor visualizado no quadro 2, com os conteúdos programáticos do ENADE realizado em 2015 e do exame de suficiência contábil (ESC) de 1/2017. 
Quadro 2. Conteúdos programáticos do ESC e ENADE.

\begin{tabular}{|l|c|c|}
\hline Conteúdos Abordados & ESC & ENADE \\
\hline Contabilidade Geral & $\mathrm{X}$ & \\
\hline Contabilidade de Custos & $\mathrm{X}$ & $\mathrm{X}$ \\
\hline Contabilidade aplicada ao setor público & $\mathrm{X}$ & $\mathrm{X}$ \\
\hline Contabilidade Gerencial & $\mathrm{X}$ & $\mathrm{X}$ \\
\hline Controladoria & $\mathrm{X}$ & $\mathrm{X}$ \\
\hline Teoria da Contabilidade & $\mathrm{X}$ & $\mathrm{X}$ \\
\hline Legislação e Ética Profissional & $\mathrm{X}$ & $\mathrm{X}$ \\
\hline Princípios em Contabilidade e Normas Brasileiras de Contabilidade & $\mathrm{X}$ & \\
\hline Auditoria Contábil & $\mathrm{X}$ & $\mathrm{X}$ \\
\hline Perícia Contábil & $\mathrm{X}$ & $\mathrm{X}$ \\
\hline Contabilidade financeira/societária; & & $\mathrm{X}$ \\
\hline Sistemas de informações contábeis; & & $\mathrm{X}$ \\
\hline Análise de demonstrações contábeis; & & $\mathrm{X}$ \\
\hline Administração financeira; & & $\mathrm{X}$ \\
\hline Métodos quantitativos aplicados à contabilidade e atuariais; & & $\mathrm{X}$ \\
\hline Noções de Direito & $\mathrm{X}$ & \\
\hline Matemática Financeira e Estatística & $\mathrm{X}$ & \\
\hline Língua portuguesa & $\mathrm{X}$ & $\mathrm{X}$ \\
\hline
\end{tabular}

Fonte: Elaboração própria.

É possível perceber que dos 18 conteúdos contidos no quadro 2, 9 são comuns entre as duas avaliações e 9 são diferentes. Entretanto, é necessário fazer uma ressalva para contabilidade geral (aplicada no exame de suficiência contábil) e a contabilidade financeira/societária (aplicada no ENADE), pois, de certa forma apresentam o mesmo assunto e podem ser consideradas equivalentes. É importante destacar que a parte geral do exame de suficiência contábil é mais completa que a do ENADE, apresentando questões acerca de noções de direito, matemática financeira, estatística e língua portuguesa enquanto o ENADE aborda a língua portuguesa em forma de dissertações sobre temas atuais.

É importante, ainda, ressaltar que o ENADE não aprova ou reprova candidatos, apenas avalia o desempenho dos estudantes nos conteúdos programáticos previstos nas diretrizes curriculares, isto é, a aptidão do estudante em estar ajustado às exigências decorrentes da evolução do conhecimento e a capacidade de entender temas externos à sua profissão (INEP, 2019). 
O CFC vem realizando vários encontros com alunos, professores e coordenadores de cursos superiores para discutir métodos de melhoria e valorização do ensino contábil nas instituições. Essa integração tem sido fundamental para o aumento da qualidade dos cursos superiores de ciências contábeis no Brasil. Dessa forma, é possível observar que existem vários fatores que influenciam o aluno a ter uma maior dedicação no curso. A obrigatoriedade do exame de suficiência contábil para a obtenção do registro profissional é um fator que pode auxiliar na melhora de desempenho dos discentes nos exames que avaliam a qualidade de ensino, como o ENADE (SOUZA, 2017).

Segundo Silva, Miranda e Freitas (2017) algumas estratégias, não diretamente ligadas a formação do aluno, podem ser utilizadas pelas organizações para buscar o aumento da sua nota no ENADE, por exemplo premiações, oferta de benefícios aos participantes de exame, aulões, seminários, palestras, dentre outros. Essas estratégias podem melhorar o nível de conhecimento dos alunos que participam de ENADE e trazer uma influência direta nas notas tiradas por alunos dessa IES no Exame de Suficiência Contábil.

Sendo assim, é possível perceber que há uma influência mútua do ENADE e Exame de Suficiência Contábil, ou seja, métodos adotados para melhorar as notas em um, influenciam no crescimento das notas do outro.

\subsection{Estudos anteriores}

Essa subseção apresentará alguns estudos que dissertam acerca do Exame de Suficiência Contábil, assim como artigos que tratam da relação entre esse tema e o Exame Nacional de Desempenho do Estudante (ENADE).

O estudo de Bugarim (2014) teve como objetivo avaliar o desempenho dos estudantes nas diversas edições do Exame de Suficiência Contábil e observou um decréscimo nos níveis de aprovação do Exame, caindo, em número de aprovações, de 83,52\% em sua primeira edição, no ano de 2000, para 23,78\% em 2012. Concluiu-se que o crescimento quantitativo das IES que ofertam o curso de ciências contábeis não acompanhou um aumento qualitativo na formação dos profissionais. Posteriormente, Alves et al. (2015), visando investigar a 
relação entre o ENADE e o Exame de Suficiência Contábil, empregou o método de regressão linear - utilizando o ESC como variável dependente e o ENADE como independente - e obteve resultados que indicaram uma relação positiva e significativa entre as variáveis, mostrando que o nível de aprovados no exame está associado às notas obtidas no ENADE.

Corroborando com essa teoria, Souza, Cruz e Lyrio (2017), mediram a correlação entre as variáveis citadas e a qualidade dos cursos superiores no Brasil, de acordo com o conceito preliminar de curso. Para tanto, utilizaram diagramas de dispersão e matriz de correlação de Pearson e chegaram a resultados semelhantes aos do artigo supracitado, apontando uma tendência moderada na associação entre o número de aprovados no Exame de Suficiência e nos indicadores do ENADE e no Conceito Preliminar de Curso, aos níveis de $69,28 \%$ e 50,47\%, respectivamente. Utilizando-se das mesmas variáveis, Souza (2017) obteve como resultado que o rendimento dos alunos de ciências contábeis está alinhado com as IES que eles escolheram para cursar o ensino superior, uma vez que o ENADE e o CPC apresentaram relações positivas com o ESC.

Por fim, num cenário mais amplo, Blum et. al (2017) objetivou relacionar o desempenho dos estados brasileiros no ENADE e no Exame de Suficiência Contábil. Foram levados em consideração os resultados das provas do ENADE aplicadas nos anos de 2012 e 2015, que posteriormente foram comparados aos do Exame de Suficiência; a correlação entre as variáveis foi calculada também aplicando a correlação de Pearson. O resultado sugere que o ENADE possui correlação com o Exame de Suficiência Contábil, porém essa correlação é moderada, visto que os resultados apresentados foram de 0,49 a 0,61 nas tentativas. 


\section{PROCEDIMENTOS METODOLÓGICOS}

\subsection{Classificação da pesquisa}

A pesquisa realizada pode ser classificada quanto à sua natureza como aplicada, pois produz conhecimento acerca da relação existente entre o desempenho no Exame de Suficiência Contábil (ESC) e no Exame Nacional de Desempenho de Estudantes (ENADE) das faculdades públicas e privadas brasileiras, gerando informações que podem ser usadas para interesses específicos e solução de problemas.

Acerca do seu objetivo é possível caracterizar a pesquisa como descritiva, tendo em vista que seu principal propósito é descrever a característica de uma população ou fenômeno, e encontrar correlação entre algumas variáveis (GIL, 2008).

Quanto ao procedimento utilizado é possível classificar a pesquisa como documental, pois, utiliza-se de dados fornecidos pelo CFC, assim como documentação disponibilizada pelo INEP. De acordo com Gil (2008), esse tipo de procedimento "vale-se de materiais que não receberam ainda um tratamento analítico, ou que ainda possam ser reelaborados de acordo com os objetivos da pesquisa”.

Finalmente, para a realização da pesquisa foram utilizados sistemas e métodos estatísticos para conseguir relacionar o desempenho dos alunos de Instituições de Ensino Superior (IES) públicas e privadas no Exame de Suficiência Contábil e Enade.

\subsection{Coleta de dados}

Para a realização do estudo, foram coletados dados referentes ao desempenho dos alunos de Instituições de Ensino Superior (IES) públicas e privadas no Exame Nacional de Desempenho de Estudantes (ENADE) e no Exame de Suficiência Contábil (ESC).

Os dados acerca do desempenho dos alunos no ENADE foram retirados do site do Instituto Nacional de Estudos e Pesquisas Educacionais Anísio Teixeira (INEP), e correspondem ao exame aplicado em 2015, ano em que houve a última divulgação de indicadores relativos ao curso de ciências contábeis. $O$ documento fornece diversas informações relativas ao exame, assim, os dados coletados foram os nomes das IES, a 
categoria administrativa pertencente, a área de enquadramento em ciências contábeis, o número de concluintes inscritos, o número de concluintes participantes e o conceito ENADE Faixa das IES.

Por sua vez, os dados referentes ao Exame de Suficiência Contábil foram obtidos no site do Conselho Federal de Contabilidade, e correspondem ao exame realizado em 1/2017, primeira vez que o CFC disponibilizou o resultado do exame separado por Instituição de Ensino Superior. A partir do documento foram coletadas informações como do nome das IES, o total de inscritos no exame, o total de presentes e o percentual de aprovação de cada instituição.

Para que fosse selecionada a amostra final do estudo foi considerada a busca no site do INEP que resultou em 1046 Instituições de Ensino Superior inscritas no ENADE de 2015, desse valor foram retiradas aquelas IES que não tiveram participantes no Exame de Suficiência Contábil de 1/2017 ou que tiveram alunos inscritos, mas não tiveram alunos presentes tanto no exame de suficiência quanto no próprio ENADE. Desta forma, houve uma redução de 155 instituições de ensino, acarretando uma amostra final de 891 Instituições de Ensino Superior.

\subsection{Análise de dados}

Inicialmente, para que fosse realizada a análise do rendimento por conceito ENADE e da aprovação no exame de suficiência contábil, foram utilizadas estatísticas descritivas que “consistem na recolha, análise e interpretação de dados numéricos através da criação de instrumentos adequados" (REIS, 1996).

Para possibilitar a análise do exame de suficiência, as IES foram divididas de acordo com a porcentagem de alunos que obtiveram êxito no exame. Foram criadas 8 classificações, apresentadas na tabela 1 . 
Tabela 1. Classificações para o exame de suficiência contábil.

\begin{tabular}{ll}
\hline Classificação & $\begin{array}{l}\text { \% de aprovados } \\
\text { por IES }\end{array}$ \\
\hline A & $0-9 \%$ \\
\hline B & $10-19 \%$ \\
\hline C & $20-29 \%$ \\
\hline D & $30-39 \%$ \\
\hline E & $40-49 \%$ \\
\hline G & $50-69 \%$ \\
\hline H & $70-89 \%$ \\
\hline & $90-100 \%$ \\
\hline
\end{tabular}

Em seguida, utilizou-se a análise de correspondência realizada pelo programa estatístico RStudio. Esta análise é um método estatístico que permite a comparação de células por meio da formação de um mapa perceptual - o qual identifica padrões que refletem associações entre certos objetos ou atributos. Para que seja criado o mapa perceptual da análise de correspondência, é necessário que antes seja feito o teste qui-quadrado.

O teste qui-quadrado é utilizado para padronizar os valores de frequência e formar a base para associações. Ele consiste em obter frequências reais das células e compará-las com frequências esperadas. A diferença entre as frequências reais e as esperadas é então elevada ao quadrado e dividida pela frequência esperada das células (HAIR Jr et. al 2009).

$$
\text { Valor qui quadrado }=\frac{\text { diferença }^{2}}{\text { frequência esperada da célula }}
$$

Após esse cálculo é necessário que o sinal da diferença original seja reincluído no valor do qui-quadrado para que seja definida a direção da similaridade (HAIR Jr et. al 2009). Os valores, então, criarão pontos no mapa perceptual da análise de correspondência.

A criação de mapas perceptuais oferece uma visão simplificada sobre quais variáveis tem certo nível de associação e quais não possuem, razão pela qual optou-se pela análise de correspondência. 


\section{RESULTADOS}

\subsection{Análise descritiva de dados}

Para iniciar as estatísticas descritivas do estudo, faz-se necessário compreender a população das Instituições de Ensino Superior que realizaram ambas as avaliações nos períodos descritos.

A quantidade total de organizações presentes no estudo foi de 891 , divididas entre públicas e privadas. No gráfico 1, é possível observar a distribuição dessas organizações de acordo com sua categoria administrativa no país.

Gráfico 1 - Quantidade total de IES públicas e privadas que realizaram ENADE e Exame de suficiência Contábil.

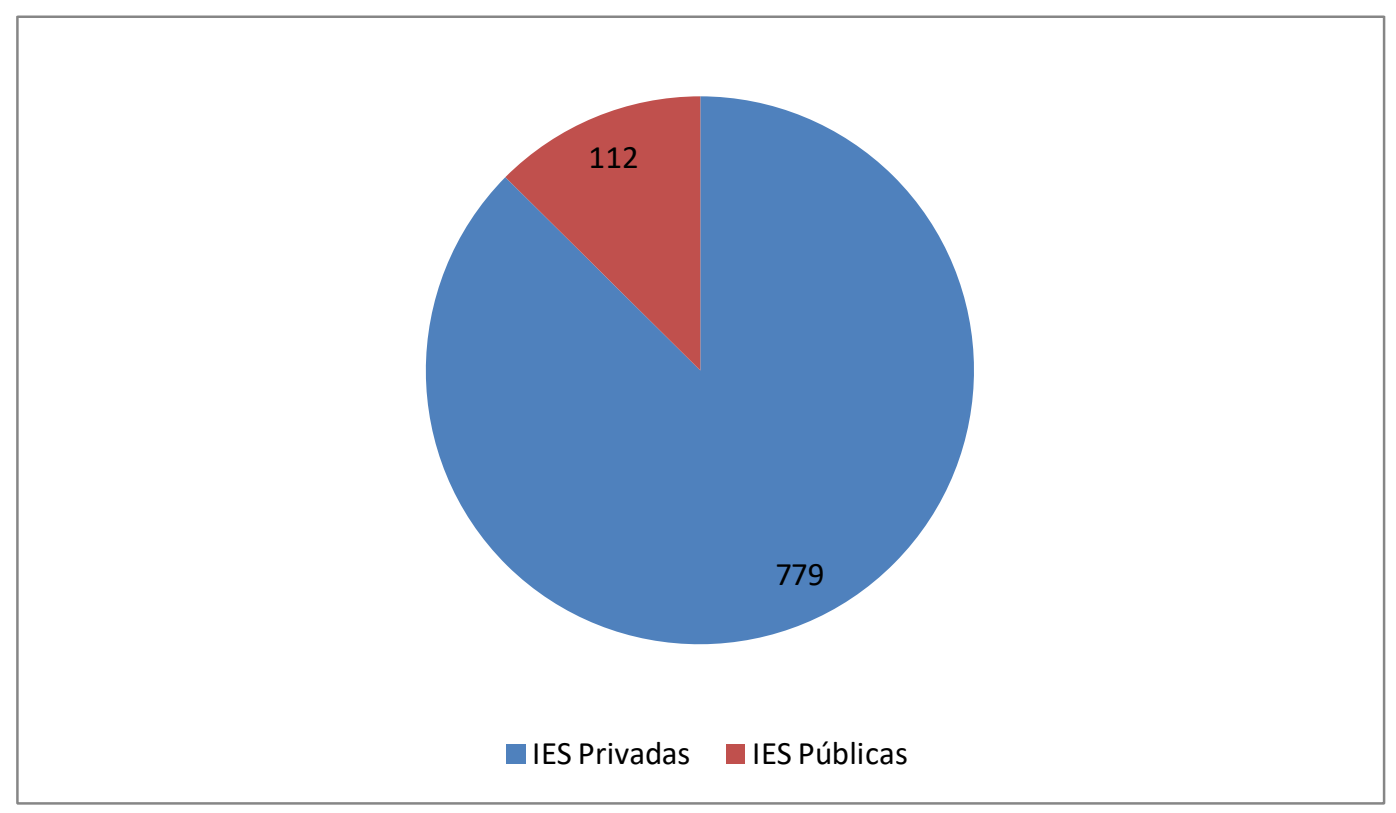

Fonte: Elaboração própria.

Observando o gráfico, é perceptível que o número de IES privadas é consideravelmente maior que o de públicas no Brasil, representando 87,43\% do total de instituições que participaram do presente estudo, ou seja, que tiveram participantes no 
ENADE e no exame de suficiência contábil, enquanto as organizações públicas representam apenas $12,57 \%$.

O gráfico 2 apresenta mais detalhadamente a quantidade de instituições de acordo com sua categoria administrativa e separadas por região.

Gráfico 2 - Quantidade de IES por região.

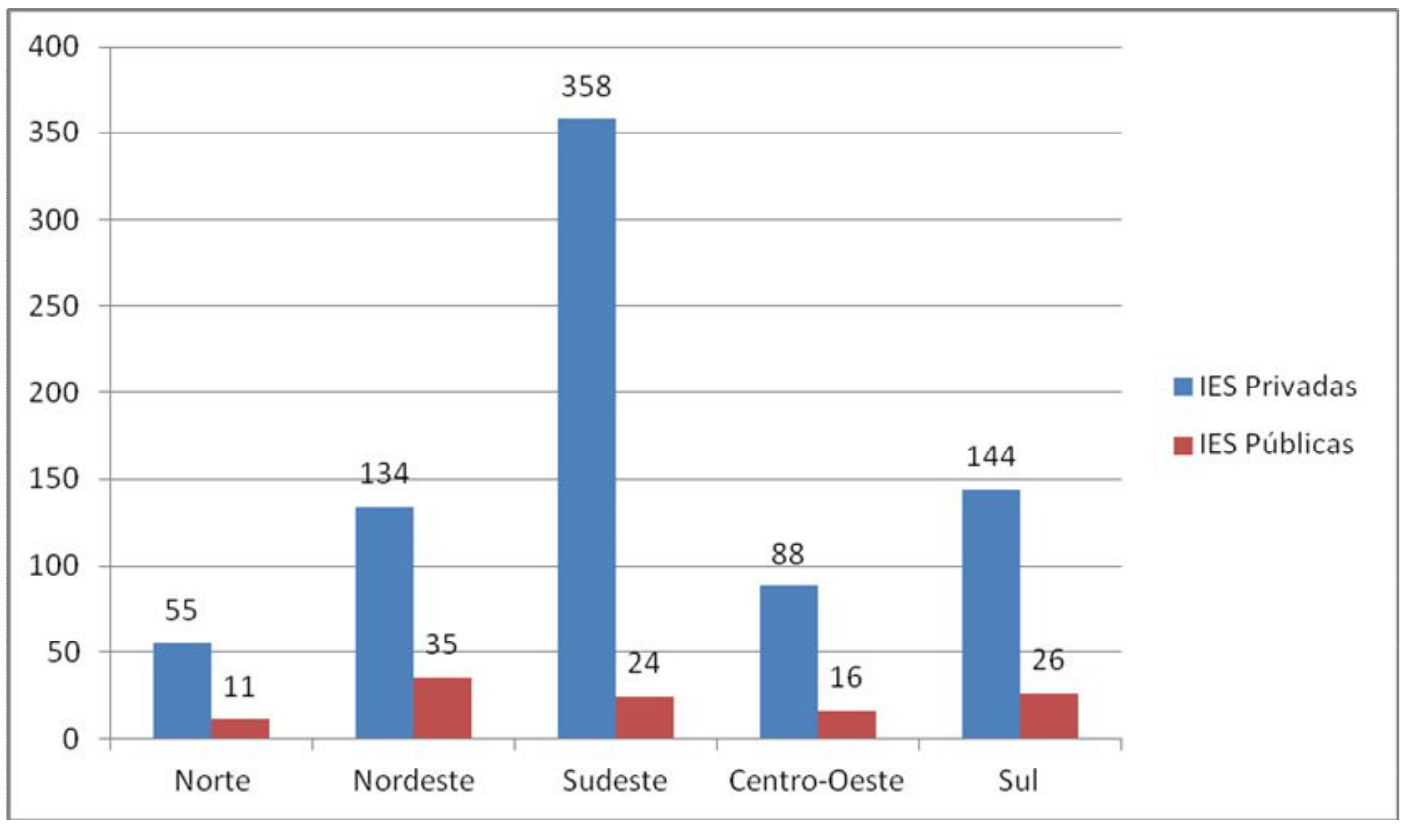

Fonte: Elaboração Própria.

É possível, assim, inferir que nos 5 estados brasileiros prevalece uma maior quantidade de organizações privadas, com destaque para a região sudeste, onde o número de organizações privadas é quase 15 vezes maior que o de públicas.

Para uma melhor visualização dos rendimentos no ENADE e no Exame de Suficiência Contábil, foram separadas as quantidades de IES públicas das IES privadas. Inicialmente, com as notas obtidas do ENADE, foram separadas as IES de acordo com sua avaliação por conceito, presente no gráfico 3 . 
Gráfico 3 - Percentual de IES públicas e privadas por conceito ENADE.

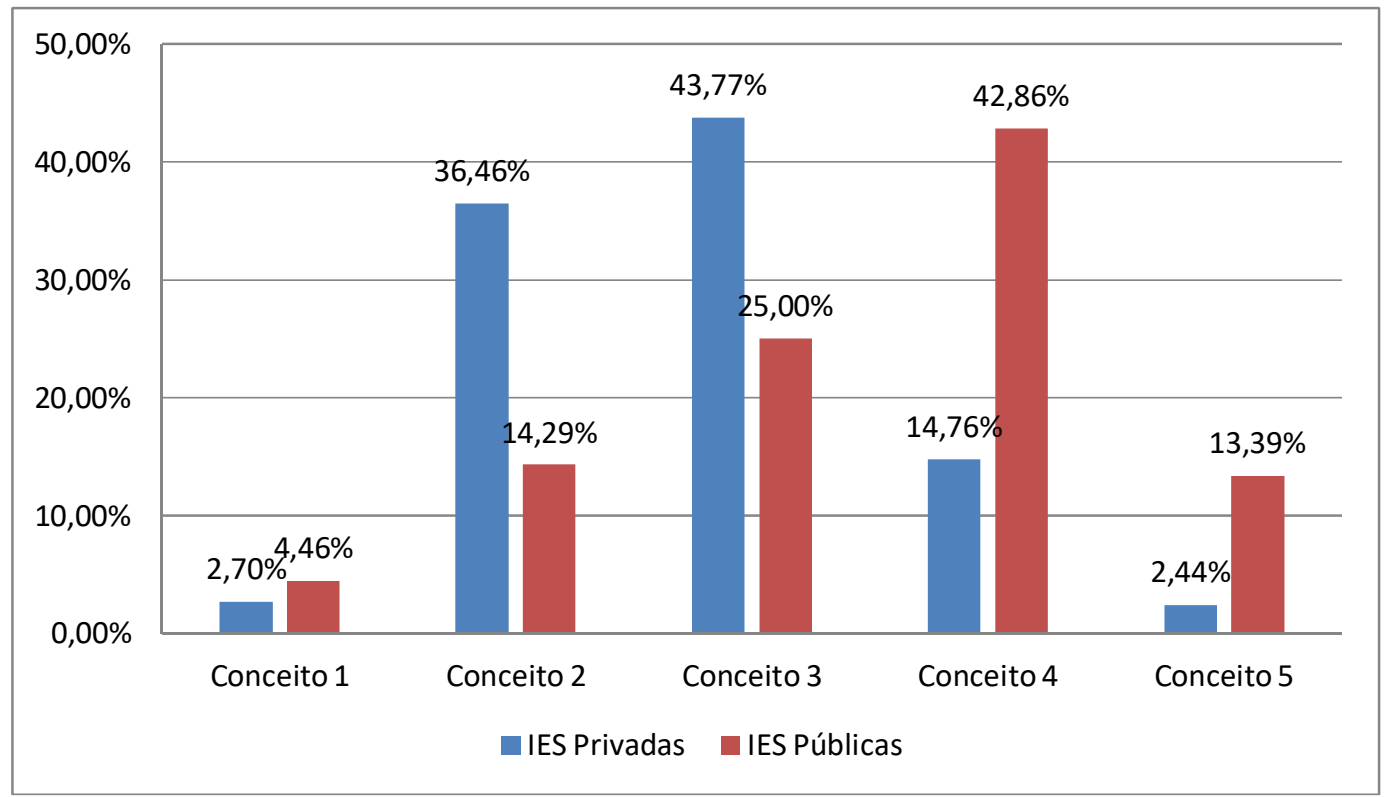

Fonte: Elaboração Própria.

De acordo com o gráfico 3, observa-se como são os rendimentos no ENADE das organizações de acordo com o conceito em que elas foram classificadas pelo INEP. Depreende-se que $82,93 \%$ das IES particulares foram classificadas até o conceito 3, tendo sua maior concentração no próprio conceito 3, com 43,77\% do total das 779 faculdades privadas presentes no estudo. Por sua vez, as instituições públicas tiveram 43,75\% de concentração nos três primeiros conceitos. Os conceitos 4 e 5 das instituições públicas abrangem $56,25 \%$ do total de 112 , sendo a maior concentração no conceito 4 , onde estão presentes $42,86 \%$ das organizações.

É importante ressaltar o baixo nível de aprovação apresentado no conceito 5, tanto para instituições públicas quanto privadas. Nesse conceito as particulares tiveram seu pior rendimento com apenas $2,44 \%$, enquanto as públicas apresentaram rendimento superior apenas ao conceito 1 , com $13,39 \%$.

O gráfico 4 foi criado com base no percentual de aprovação dos alunos das IES públicas e privadas no exame de suficiência contábil e leva em consideração a divisão das organizações presente na tabela 1 . 
Gráfico 4 - Percentual de IES públicas e privadas por índices de aprovação no exame do CFC.

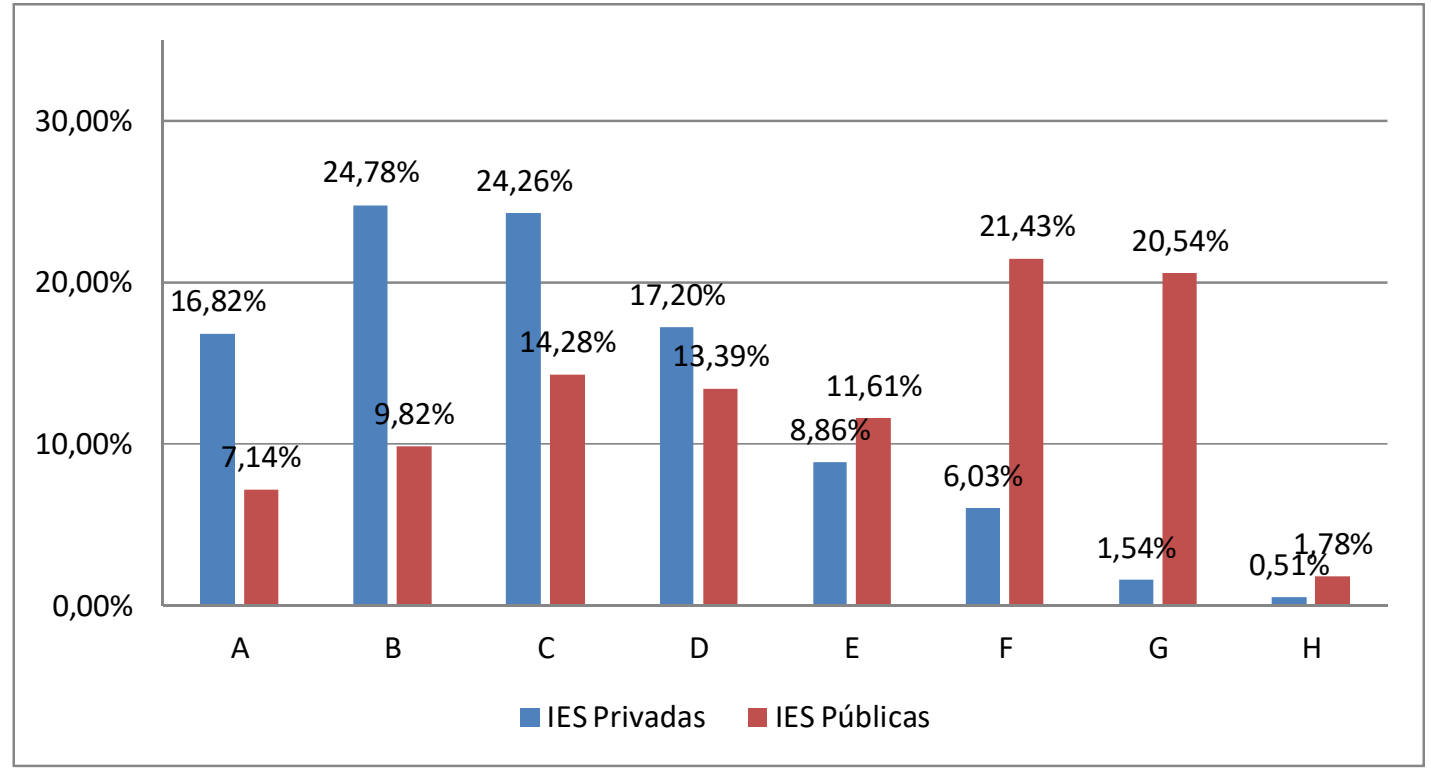

Fonte: Elaboração Própria.

Por meio do gráfico 4, é possível verificar uma inversão de percentuais entre as duas variáveis - as entidades de categoria administrativa privada estão majoritariamente alocadas entre as cinco primeiras classificações, estando 91,92\% das organizações compreendidas em até $49,99 \%$ de aprovação no exame de suficiência contábil. Apenas 8,08\% das instituições particulares, portanto, aprovam mais de $50 \%$ de seus alunos, possuindo seu maior índice na classificação B, que abrange IES que têm de 10 a 19\% de aprovação no exame. Por outro lado, a rede de ensino pública possui $56,24 \%$ de suas instituições classificadas até o item E, isto é, $46,76 \%$ das IES públicas aprovam pelo menos metade dos alunos que realizam as provas do exame do CFC. Já a qualificação com maior concentração de alunos advindos de organizações públicas é a F (de 50 a 69\%), com um total de 21,43\% das 112 faculdades.

Por fim, é importante destacar o baixo número de IES na classificação H. Pode-se observar na tabela 1 que apenas 6 organizações integram essa qualificação, sendo 4 privadas e 2 públicas. É preciso, no entanto, fazer uma ressalva acerca do número de participantes que obtiveram êxito no exame e estão nessa qualificação: as duas instituições públicas foram responsáveis pelo sucesso de 51 estudantes, enquanto as quatro organizações privadas foram 
responsáveis pelo êxito de 30 estudantes, sendo uma dessas quatro organizações responsável pelo sucesso de apenas 1 aluno.

\subsection{Análise de correspondência dos dados}

O gráfico 5 representa o mapa perceptual das 112 instituições de ensino superior públicas presentes no estudo, apresentando a associação entre as notas que essas instituições tiraram no ENADE e a notas com que foram classificadas no Exame de Suficiência Contábil de acordo com as categorias previamente estabelecidas.

Gráfico 5. Mapa perceptual segundo categoria administrativa pública.

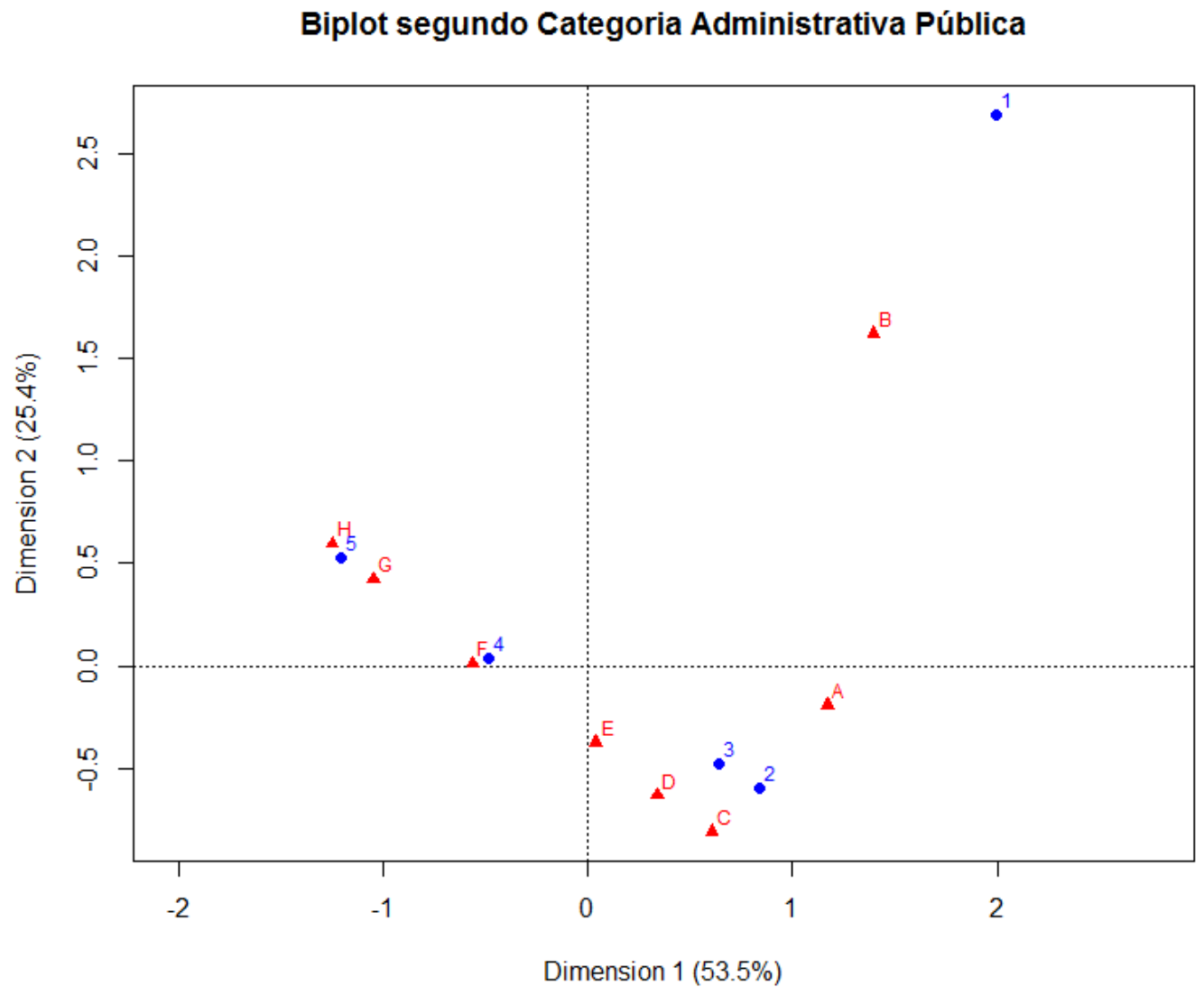

Fonte: Elaboração Própria. 
A partir da análise do mapa, nota-se que a categoria H (que representa as IES tiveram entre 90 e 100\% de aprovação no ESC) apresenta maior associação com as instituições que possuem conceito 5 no ENADE. O conceito 5 também pode ser associado à categoria $\mathrm{G}$ (dos que obtiveram entre 70 e $89 \%$ de aprovação), entretanto, é notório que a proximidade existente entre o conceito 5 e a categoria $\mathrm{G}$ é maior que a proximidade entre o conceito 5 e a categoria $\mathrm{H}$, sendo assim, pode-se dizer que a classificação $\mathrm{G}$, apesar de associada ao conceito 5, apresenta uma associação mais fraca do que a associação de conceito 5-H.

O conceito 4 aparece com forte associação à categoria $\mathrm{F}$, que representa de 50 a $69 \%$ de aprovação no ESC. O conceito 3 e 2 apresentam certa associação com as categorias D e C, respectivamente.

De acordo com o mapa, o conceito 1 e a categoria B (10 a 19\%) não possuem fortes associações, indicando pouca similaridade entre os resultados dessas IES com os das outras.

O gráfico 6 representa o mapa perceptual das 779 instituições de ensino superior privadas presentes no estudo. 
Gráfico 6. Mapa perceptual segundo categoria administrativa privada.

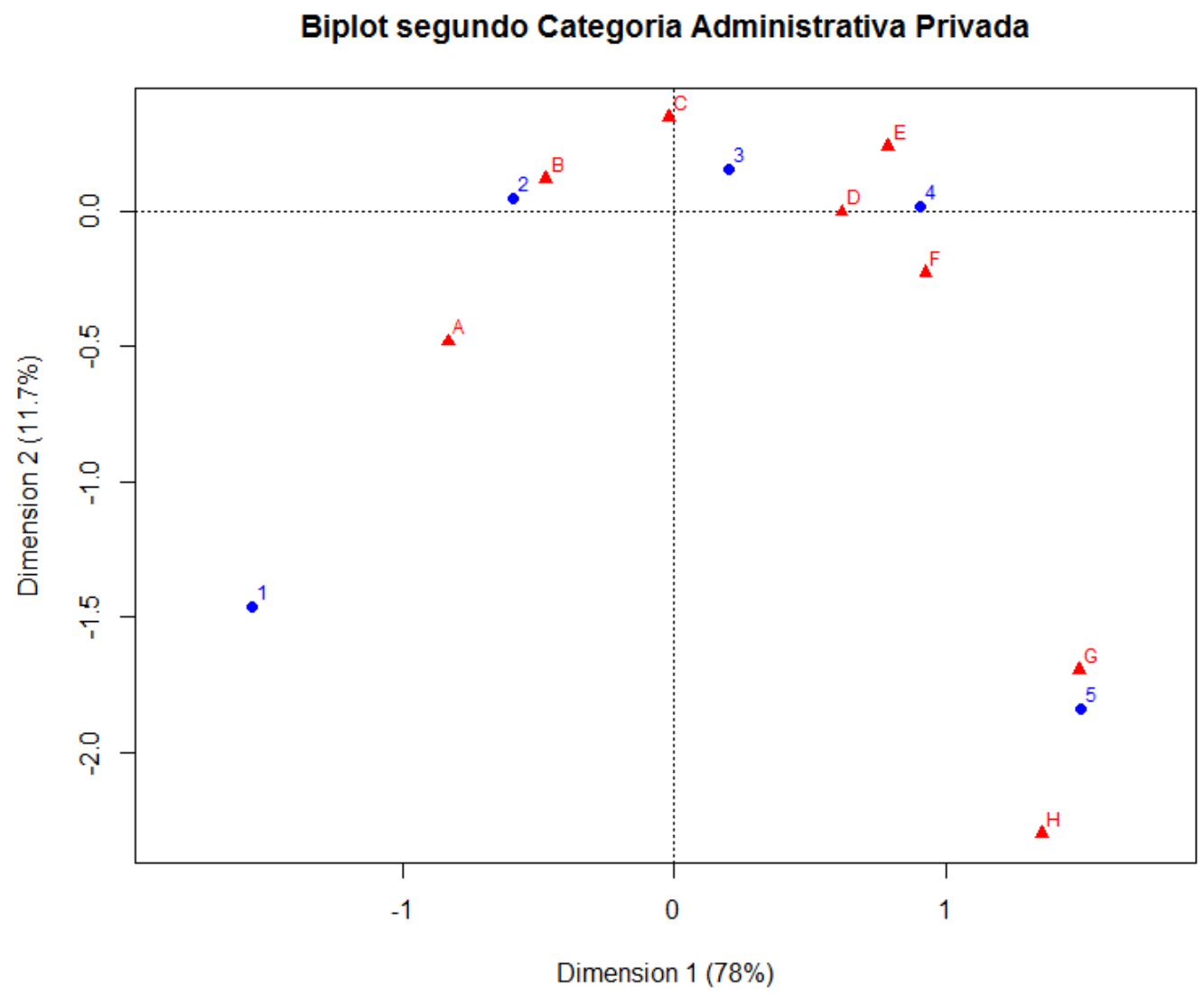

Fonte: Elaboração Própria.

Denota-se a existência de uma associação forte entre as IES que estão classificadas no conceito 2 do ENADE e as que estão na categoria B (de 10 a 19\%) do ESC. Outra forte associação é vista no conceito 5 do ENADE e na categoria G (de 70 a 89\%).

O conceito 3 possui associação com as categorias C (20 a 29\%), D (30 a 39\%) e E (40 a $49 \%$ ), dentre as quais a primeira categoria é a que apresenta maior associação com o conceito.

O conceito 4 possui associações com as categorias $\mathrm{D}$, E e F. A categoria $\mathrm{H}$ tem menor associação com os conceitos, tendo em vista que, de acordo com o apêndice $B$, se posiciona 
em $-5,92$ na dimensão 2 . O conceito 1 , por sua vez, não possui forte associação com as outras categorias.

O gráfico 7 representa o mapa perceptual de três variáveis: a categoria administrativa, o conceito ENADE e o Exame de Suficiência Contábil. Os resultados foram obtidos a partir de uma análise de correspondência múltipla, que padroniza e cria similaridades entre os resultados.

Gráfico 7. Mapa perceptual de análise de correspondência múltipla.

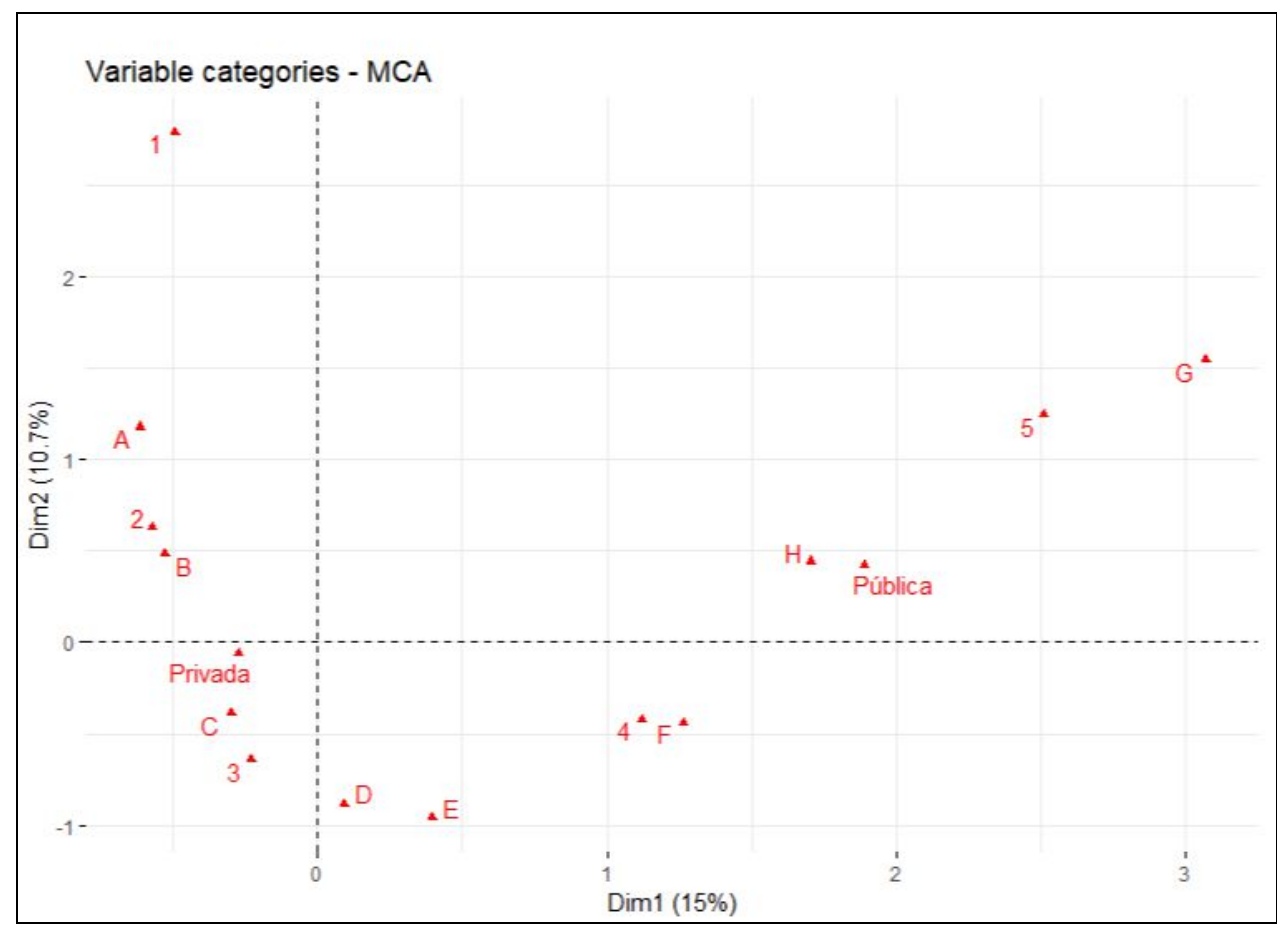

Fonte: Elaboração Própria.

Ao integrar as três variáveis nessas dimensões, infere-se que algumas associações gerais podem ser feitas - o conceito ENADE 2 é fortemente associado à categoria $\mathrm{B}$ (de $10 \mathrm{a}$ 19\%) do Exame de Suficiência; o conceito 3 tem sua maior associação com a categoria C (de 20 a 29\%); o conceito 4 tem associação forte com a categoria $F$ (de 50 a 69\%), e o conceito 5 , assim como o conceito 1 , não possui qualquer associação forte o suficiente para ser destacada. 
Com relação à variável de categoria administrativa e ENADE é possível perceber que o conceito ENADE 1 está pouco associado tanto às instituições de ensino públicas quanto às privadas; já o conceito ENADE 2 está pouco associado às IES públicas possuindo maior associação com as IES privadas, enquanto o conceito 3 é o mais associado às instituições de ensino privadas e tem associação mais fraca com as públicas; o conceito 4 tem associação fraca tanto com públicas quanto com privadas e o conceito 5, apesar de não ter forte associação, é o que mais se aproxima das IES públicas.

Ainda sobre a categoria administrativa, mas com relação ao Exame de Suficiência Contábil, o gráfico indica que as instituições privadas possuem associações mais fortes com a categoria C (de 20 a 29\% de aprovação no ESC), enquanto as públicas têm associações fortes com a categoria H (de 90 a 100\%). O restante das categorias não apresentou associação forte com nenhuma das categorias administrativas.

Infere-se, a partir do mapa perceptual gerado pela análise de correspondência múltipla, que as Instituições de Ensino Superior privadas possuem mais associação com o conceito ENADE 3 e possuem, geralmente, de 20 a 29\% de aprovação no Exame de Suficiência Contábil já que se relacionam mais com a categoria C. Em contrapartida, as instituições públicas detêm maior associação com o conceito ENADE 5 e possuem associação forte com relação ao Exame de Suficiência Contábil com o nível de aprovação de 90 a 100\%. 


\section{CONCLUSÃO}

A partir da análise minuciosa dos dados, verificou-se a existência de relação entre os resultados do Exame de Suficiência Contábil e do Exame Nacional de Desempenho dos Estudantes (ENADE), ratificando a visão sugerida por estudos anteriores.

No que tange à comparação entre as faculdades públicas e privadas, foram envolvidas 891 IES, constituídas por 112 públicas e 779 privadas. Inicialmente, foi realizada uma análise descritiva que mostrou que $82,93 \%$ das faculdades particulares foram classificadas até o conceito ENADE 3, sendo que o maior número de IES está presente no próprio conceito 3 com $43,77 \%$, enquanto nas faculdades públicas, a maior concentração é no conceito 4 , com $42,86 \%$.

Para a análise do Exame de Suficiência, foram criadas 8 classificações e atribuídos valores percentuais a elas. Assim, observou-se que quase $92 \%$ das faculdades privadas aprovam menos de 50\% de seus alunos no exame, obtendo maior concentração de aprovações entre 10 e 19\%, enquanto 46,6\% das IES públicas superam a média nesse quesito.

De acordo com a análise de correspondência múltipla aplicada no estudo, foi possível observar a existência de associações nas 3 variáveis utilizadas - categoria administrativa, ENADE e Exame de Suficiência Contábil. O mapa perceptual mostra que a as instituições de ensino superior privadas têm associação maior com o conceito ENADE 3 e com a categoria C do ESC, que tem de 20 a $29 \%$ de aprovação no exame. Já as instituições de ensino públicas possuem maior associação com o conceito ENADE 5 e com a categoria H do ESC, que representa aquelas que têm de 90 a 100\% de aprovação no exame.

Como limitação do estudo, destaca-se o período em que foi possível ter acesso aos dados. O ENADE ocorre trienalmente e os resultados do ano de 2018 ainda não foram divulgados, portanto foram utilizados os resultados da prova realizada em 2015. Por sua vez, o Exame de suficiência contábil já conta com a divulgação de dados desde 2011, porém, só começou a divulgar os dados com separação por IES a partir do primeiro exame de 2017, sendo assim, foram utilizados os dados de 1/2017.

Sugere-se para pesquisas futuras, uma análise para o próximo triênio do ENADE, utilizando os dados de 2018 fornecidos pelo CFC com os dados do mesmo ano fornecidos pelo INEP. 
Esse estudo pode contribuir para a área de educação em contabilidade no tocante à melhoria de qualidade de ensino no país, tendo em vista que apresentou importantes dados comparativos entre dois significativos objetos de avaliação aos que as IES são submetidas e identifica diferenças entre os setores público e privado, fornecendo dados que podem auxiliar na melhoria da gestão dessas organizações. 


\section{REFERÊNCIAS}

ALVES, E. M.; YOSHITAKE, F. M.; SALLES, J. A. A. Relationship Between the National Survey of Development of Students (ENADE) and Testing of Sufficiency Federal Council of Accounting (FCA). Procedia-Social and Behavioral Sciences, v. 174, p. 2967-2974, 2015.

BLUM, G.; WEBER, L.; FAGUNDES, E.; MAES, M. A.; ADAMCZYK, W. B. Relação Enade x CFC: uma análise do desempenho dos estados brasileiros. XV Congresso USP de iniciação científica em contabilidade. Universidade de São Paulo, 2018.

BROIETTI, C. Exame de Suficiência do Conselho Federal de Contabilidade: Observação das Publicações Relacionadas ao Tema. Congresso UFSC de controladoria e finanças \& iniciação científica em contabilidade, Apucarana, 2014.

BUGARIM, M. C. C.; RODRIGUES, L. L.; PINHO, J. C. C.; MACHADO, D. Q. Análise histórica dos resultados do Exame de Suficiência do Conselho Federal de Contabilidade.

Revista Contabilidade e Controladoria, v.6, n.1, p.121-136, 2014.

CONSELHO FEDERAL DE CONTABILIDADE. Caderno analítico do exame de suficiência: histórico dos resultados. Brasília: CFC, 2007.

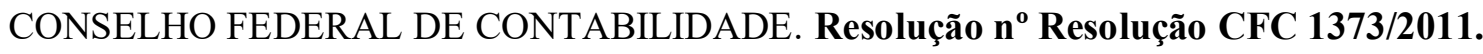

GIL, A. C. Métodos e técnicas da pesquisa social. 6 ed. São Paulo: Atlas, 2008.

HAIR JR, J. F.; BLACK, W. C.; BABIN, B. J.; ANDERSON, R. E.; TATHAM, R. L.

Análise Multivariada de Dados. 6 ed. Porto Alegre: Bookman, 2009.

INEP (Instituto Nacional De Estudos E Pesquisas Educacionais). Nota técnica $\mathbf{n}^{\mathbf{0}}$ 2/2017/CGCQES/DAES. 2017.

INEP (Instituto Nacional De Estudos E Pesquisas Educacionais). 2015. ENADE. Disponível em $<$ http://inep.gov.br/enade>. Acesso em 15 de março de 2019.

JESUS, R. Desempenho no ENADE: comparação das instituições públicas e privadas do curso de ciências contábeis no Brasil. Universidade de Rio Verde - UniRV. Rio Verde, Goiás, 2017.

Lei n. 10.861, de 14 de abril de 2004. Institui o Sistema Nacional de Avaliação da Educação Superior - Sinaes e dá outras providências. Brasília. Disponível em $<$ http://www.planalto.gov.br/ccivil_03/_ato2004-2006/2004/lei/110.861.htm>. Acesso em 15 de março de 2019.

MARTINS, C. M. F.; SILVA, C. B. A.; BERNARDO, D. C. R.; MADEIRA, G. J. O desempenho do estado de Minas Gerais no sétimo exame de suficiência do CFC - Março 2003. Contabilidade Vista \& Revista, Belo Horizonte, p. 81-102, 2009.

OLIVEIRA NETO, J. D.; KUROTORI, I. K. O Retorno do Exame de Suficiência do CFC. Revista de Contabilidade do Mestrado em Ciências Contábeis da UERJ, Rio de Janeiro, v. 14, n. 1, p.1-18, 2009. 
PAIVA, J. C. L. S.; \& ROSA, P. M. Os Processos de Avaliação Educacional no Brasil e seu Reflexo na Melhoria do Ensino nas Instituições de Ensino Superior nos Cursos de Ciências Contábeis. Revista UNIFAMMA, v.15, n. 1, p. 92-112, 2016.

PINHEIRO, F. M. G.; FILHO, J. M. D.; FILHO, R.N. L.; LOPES, L. M. S.; O perfil do contador e os níveis de habilidades cognitivas nos exames Enade e suficiência do CFC: uma análise sob a perspectiva da taxonomia de Bloom. Revista Contemporânea de Economia e Gestão. v. 11, n. 1, 2013.

PINHEIRO, L. B.; BONFIM, M. P; PORTUGAL, G. T. Um estudo sobre a Aplicação dos Conteúdos da Contabilidade Gerencial e de Custos nos Exames de Suficiência de 2011 e 2012. Pensar Contábil, Rio de Janeiro, v. 15, n. 57, p. 43-49, 2013.

REIS, E. Estatística Descritiva. Lisboa: Edições Sílabo, 1996.

SANTOS, N. A.; AFONSO, L. E. Análise do conteúdo das provas da área de Ciências Contábeis: edições do Provão 2002/2003 e do ENADE de 2006. Rev. Avaliação (Campinas). v. 21, n. 2, p. 387-414, 2016.

SANTOS, M. J.; PINHEIRO, L.B.; OLIVEIRA, J.W.; SILVA, S.G.; NOGUEIRA, M. S.; LIMA, A. V.; TERRA, B. Um estudo comparativo entre o exame de suficiência do conselho federal de contabilidade, o exame nacional de desempenho de estudantes e a pós-graduação stricto sensu dos cursos de ciências contábeis do estado do rio de janeiro. Rev. Polêm!ca, v. 13, n. 4, p. 1681-1698, 2014.

SCHMITZ, J. Do currículo aos exames nacionais: uma análise da aderência do currículo do curso de ciências contábeis da UFSC às diretrizes curriculares nacionais, ao ENADE e ao exame de suficiência do CFC. Dissertação de Mestrado - Programa de Pós-Graduação em Contabilidade, Universidade Federal de Santa Catarina, Florianópolis, 2008.

SILVA, L.A. Mostrar a visão do aluno de ciências contábeis sobre o Enade, e a atribuição de uma boa nota do curso na Paraíba. Trabalho de Conclusão de Curso (Graduação em Ciências Contábeis)- Universidade Estadual da Paraíba, Monteiro, 2015.

SILVA, M. C. P. Estudo das exigências programáticas nos exames de suficiência e provas do Enade para o curso de Ciências Contábeis. Trabalho de Conclusão de Curso Faculdade de Administração, Economia e Ciências Contábeis, Goiânia, 2015.

SILVA, V.; MIRANDA, G.; PEREIRA, J. ENADE e Proposta Curricular do CFC: Um Estudo em Cursos Brasileiros de Ciências Contábeis. Revista De Educação E Pesquisa Em Contabilidade (REPeC), v. 11, n. 3, 2017.

SILVA, T. D., MIRANDA, G. J., \& FREITAS, S. C. Ações Institucionais Preparatórias para o ENADE nos Cursos de Ciências Contábeis. Revista Universo Contábil, v. 13, n. 1, p. 65 84, 2017.

SOUZA, P. V. S. A Relação do Exame de Suficiência Contábil com o ENADE e o Conceito Preliminar de Curso das IES do Brasil. Congresso UnB de contabilidade e governança. Universidade Federal Rural da Amazônia, 2017.

SOUZA, P. V. S., CRUZ, U. L., \& LYRIO, E. F. A Relação do Exame de Suficiência Contábil com o Desempenho Discente e a Qualidade dos Cursos Superiores em Ciências Contábeis do Brasil. Revista Ambiente Contábil, v. 9, n. 2, p. 179-199, 2017. 
APÊNDICE A - Dados R da categoria administrativa pública referentes ao gráfico 5

Tabela 3. Inércias principais (autovalores)

\begin{tabular}{lcccc}
\hline & 1 & 2 & 3 & 4 \\
\hline Value & $\mathbf{0 . 4 5 9 6 8 1}$ & $\mathbf{0 . 2 1 8 3 0 5}$ & $\mathbf{0 . 1 2 6 8 2}$ & $\mathbf{0 . 0 5 4 1 5 2}$ \\
\hline Percentage & $\mathbf{5 3 . 5 2 \%}$ & $\mathbf{2 5 . 4 2 \%}$ & $\mathbf{1 4 . 7 6 \%}$ & $\mathbf{6 . 3 \%}$
\end{tabular}

Tabela 4. Linhas

\begin{tabular}{lccccc}
\hline & 1 & 2 & 3 & 4 & 5 \\
\hline Mass & 0.044643 & 0.142857 & 0.250000 & 0.428571 & 0.133929 \\
\hline ChiDist & 2.465028 & 1.085295 & 0.767536 & 0.464446 & 1.158344 \\
& & & & & \\
\hline Inertia & 0.271266 & 0.168266 & 0.147278 & 0.092447 & 0.179700 \\
\hline Dim. 1 & 2.420709 & 1.022247 & 0.780008 & -0.589649 & -1.466437 \\
\hline Dim. 2 & 3.934493 & -0.869143 & -0.697001 & 0.047053 & 0.766086 \\
\hline
\end{tabular}

Tabela 5. Colunas

\begin{tabular}{lcccccccc}
\hline & A & B & C & D & E & F & G & H \\
\hline Mass & $\mathbf{0 . 0 7 1 4 2 9}$ & 0.098214 & 0.142857 & 0.133929 & 0.116071 & 0.214286 & 0.205357 & 0.017857 \\
& & & & & & & & \\
\hline ChiDist & 1.477611 & 1.620461 & 0.763763 & 0.541603 & 0.539559 & 0.601695 & 0.949712 & 1.204159 \\
& & & & & & & & \\
\hline Inertia & 0.155952 & 0.257900 & 0.083333 & 0.039286 & 0.033791 & 0.077579 & 0.185223 & 0.025893 \\
\hline Dim. 1 & 1.423733 & 1.695610 & 0.734742 & 0.413855 & 0.046610 & -0.679764 & -1.272361 & -1.516293 \\
\hline Dim. 2 & $-\mathbf{- 0 . 2 8 3 8 9 8}$ & $\mathbf{2 . 3 6 8 8 7 3}$ & -1.185757 & -0.928464 & -0.548363 & 0.012308 & 0.617637 & 0.870168 \\
\hline
\end{tabular}


APÊNDICE B - Dados R da categoria administrativa privada referentes ao gráfico 6

Tabela 6. Inércias principais (autovalores)

\begin{tabular}{lcccc}
\hline & 1 & 2 & 3 & 4 \\
\hline Value & 0.150913 & 0.022694 & 0.011918 & 0.008028 \\
\hline Percentage & $77.97 \%$ & $11.72 \%$ & $6.16 \%$ & $4.15 \%$ \\
\hline
\end{tabular}

Tabela 7. Linhas

\begin{tabular}{lccccc}
\hline & 1 & 2 & 3 & 4 & 5 \\
\hline Mass & 0.026958 & 0.365854 & 0.435173 & 0.147625 & 0.024390 \\
\hline ChiDist & 1.188587 & 0.378736 & 0.170015 & 0.602842 & 1.227691 \\
\hline Inertia & $\mathbf{0 . 0 3 8 0 8 4}$ & $\mathbf{0 . 0 5 2 4 7 9}$ & $\mathbf{0 . 0 1 2 5 7 9}$ & $\mathbf{0 . 0 5 3 6 5 0}$ & $\mathbf{0 . 0 3 6 7 6 2}$ \\
\hline Dim. 1 & $-\mathbf{2 . 4 9 7 4 2 7}$ & $\mathbf{- 0 . 9 5 1 3 3 9}$ & $\mathbf{0 . 3 2 5 0 2 7}$ & 1.459043 & 2.400179 \\
\hline Dim. 2 & $-\mathbf{- 3 . 7 5 9 2 6 5}$ & $\mathbf{0 . 1 1 2 7 3 9}$ & $\mathbf{0 . 3 9 0 5 8 4}$ & $\mathbf{0 . 0 3 8 6 8 0}$ & $-\mathbf{4 . 7 3 9 0 6 3}$ \\
\hline
\end{tabular}

Tabela 8. Colunas

\begin{tabular}{|ccccccccc}
\hline & A & B & C & D & E & F & G & H \\
\hline Mass & $\mathbf{0 . 1 6 8 1 6 4}$ & $\mathbf{0 . 2 4 7 7 5 4}$ & $\mathbf{0 . 2 4 2 6 1 9}$ & $\mathbf{0 . 1 7 2 0 1 5}$ & $\mathbf{0 . 0 8 8 5 7 5}$ & $\mathbf{0 . 0 6 0 3 3 4}$ & $\mathbf{0 . 0 1 5 4 0 4}$ & $\mathbf{0 . 0 0 5 1 3 5}$ \\
\hline ChiDist $\mathbf{0 . 5 6 0 3 7 1}$ & $\mathbf{0 . 3 0 5 7 1 5}$ & $\mathbf{0 . 1 6 2 8 8 0}$ & $\mathbf{0 . 3 9 7 0 2 9}$ & $\mathbf{0 . 5 2 6 7 7 4}$ & $\mathbf{0 . 5 9 2 2 4 7}$ & 1.238734 & 1.689701 \\
\hline Inertia & $\mathbf{0 . 0 5 2 8 0 6}$ & $\mathbf{0 . 0 2 3 1 5 5}$ & $\mathbf{0 . 0 0 6 4 3 7}$ & $\mathbf{0 . 0 2 7 1 1 5}$ & $\mathbf{0 . 0 2 4 5 7 9}$ & $\mathbf{0 . 0 2 1 1 6 2}$ & $\mathbf{0 . 0 2 3 6 3 7}$ & $\mathbf{0 . 0 1 4 6 6 0}$ \\
\hline Dim. 1 & -1.334798 & $-\mathbf{0 . 7 5 9 2 9 0}$ & $\mathbf{- 0 . 0 3 2 7 0 9}$ & $\mathbf{0 . 9 9 1 3 7 5}$ & $\mathbf{1 . 2 6 6 2 3 4}$ & $\mathbf{1 . 4 8 7 9 2 6}$ & $\mathbf{2 . 3 9 5 6 8 8}$ & 2.172122 \\
\hline Dim. 2 & $-\mathbf{1 . 2 4 0 8 9 2}$ & $\mathbf{0 . 3 0 3 5 8 2}$ & $\mathbf{0 . 8 8 7 7 3 0}$ & $\mathbf{- 0 . 0 1 4 6 8 9}$ & $\mathbf{0 . 6 0 7 8 9 6}$ & $\mathbf{- 0 . 5 9 0 4 9 9}$ & $-\mathbf{- 4 . 3 6 3 1 8 4}$ & $\mathbf{- 5 . 9 2 0 0 6 9}$ \\
\hline
\end{tabular}


APÊNDICE C - Dados R da análise de correspondência múltipla referentes ao gráfico 7

Tabela 9. Autovalores

Dim.1 Dim.2 Dim.3 Dim.4 Dim.5 Dim.6 Dim.7 Dim.8 Dim.9 Dim.10 Dim.11 Dim.12

\begin{tabular}{lcccccccccccc}
\hline Variance & 0.599 & 0.426 & 0.377 & 0.360 & 0.334 & 0.333 & 0.333 & 0.309 & 0.295 & 0.251 & 0.217 & 0.164 \\
\hline \% of var. & 14.979 & 10.661 & 9.427 & 9.010 & 8.343 & 8.333 & 8.333 & 7.730 & 7.374 & 6.272 & 5.433 & 4.104 \\
& & & & & & & & & & & & \\
\hline Cumul. var. 14.979 & 25.640 & 35.067 & 44.077 & 52.420 & 60.754 & 69.087 & 76.817 & 84.191 & 90.463 & 95.896 & 100.000
\end{tabular}

Tabela 10. Indivíduos (10 primeiros)

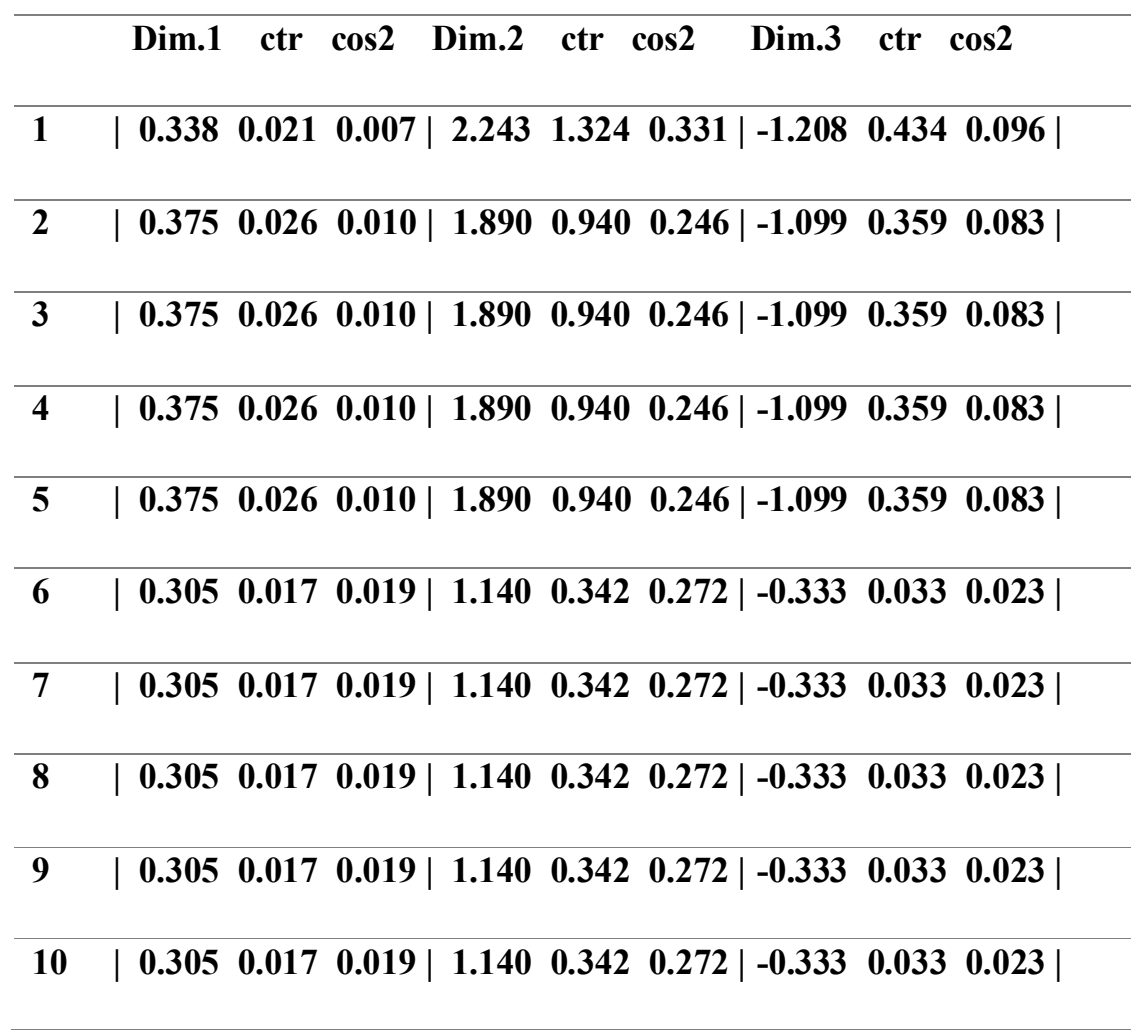


Tabela 11. Categorias (10 primeiras)

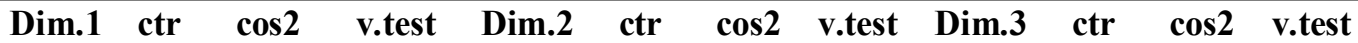

\begin{tabular}{lllllllllllll}
\hline Privada & -0.272 & 3.594 & 0.514 & -21.388 & -0.061 & 0.254 & 0.026 & -4.801 & 0.047 & 0.168 & 0.015 & 3.665
\end{tabular}

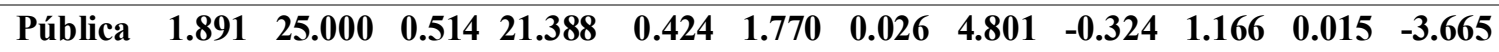

\begin{tabular}{llllllllllllll}
\hline 1 & & -0.493 & 0.395 & 0.007 & -2.550 & 2.790 & 17.758 & 0.234 & 14.432 & -1.584 & 6.475 & 0.075 & -8.194
\end{tabular}

$\begin{array}{llllllllllllll}2 & -0.569 & 6.090 & 0.165 & -12.130 & 0.630 & 10.470 & 0.202 & 13.417 & 0.028 & 0.024 & 0.000 & 0.603\end{array}$

$\begin{array}{lllllllllllll}3 & -0.229 & 1.198 & 0.037 & -5.709 & -0.642 & 13.276 & 0.289 & -16.033 & 0.301 & 3.292 & 0.063 & 7.507\end{array}$

\begin{tabular}{llllllllllllll}
\hline 4 & 1.121 & 12.796 & 0.281 & 15.828 & -0.421 & 2.540 & 0.040 & -5.949 & -1.033 & 17.265 & 0.239 & -14.585
\end{tabular}

\begin{tabular}{llllllllllllll}
\hline 5 & & 2.509 & 13.369 & 0.250 & 14.912 & 1.244 & 4.613 & 0.061 & 7.390 & 2.669 & 24.025 & 0.283 & 15.858
\end{tabular}

$\begin{array}{lllllllllllllll}\text { A } & & -0.614 & 3.270 & 0.070 & -7.873 & 1.179 & 16.941 & 0.257 & 15.118 & -0.317 & 1.385 & 0.019 & -4.065\end{array}$

\begin{tabular}{lllllllllllllll}
\hline B & & -0.526 & 3.521 & 0.082 & -8.547 & 0.488 & 4.266 & 0.071 & 7.937 & -0.116 & 0.270 & 0.004 & -1.879
\end{tabular}

$\begin{array}{llllllllllllll}C & & -0.299 & 1.142 & 0.027 & -4.870 & -0.383 & 2.633 & 0.044 & -6.240 & 0.442 & 3.971 & 0.058 & 7.206\end{array}$

Tabela 12. Variáveis categóricas (eta2)

\begin{tabular}{lccc}
\hline & Dim.1 & Dim.2 & Dim.3 \\
\hline Categoria Administrativa & 0.514 & 0.026 & 0.015 \\
\hline Enade & 0.608 & 0.622 & 0.578 \\
\hline ESC & 0.675 & 0.631 & 0.538 \\
\hline
\end{tabular}

